\title{
HIV-associated Kaposi's sarcoma in Maputo, Mozambique: outcomes in a specialized treatment center, 2010-2015
}

Vini Fardhdiani ${ }^{1}$, Lucas Molfino ${ }^{1}$, Ana Gabriela Zamudio ${ }^{1}$, Rolanda Manuel ${ }^{2}$, Gilda Luciano ${ }^{2}$, Iza Ciglenecki ${ }^{3}$, Barbara Rusch ${ }^{3}$, Laurence Toutous Trellu ${ }^{4}$ and Matthew E Coldiron ${ }^{5^{*}}$

\begin{abstract}
Background: Kaposi's sarcoma (KS) is a common HIV-associated malignancy associated with disability, pain and poor outcomes. The cornerstone of its treatment is antiretroviral therapy, but advanced disease necessitates the addition of chemotherapy. In high-income settings, this often consists of liposomal anthracyclines, but in Mozambique, the first line includes conventional doxorubicin, bleomycin and vincristine, which is poorly-tolerated. Médecins Sans Frontières supports the Ministry of Health $(\mathrm{MOH})$ in a specialized HIV and KS treatment center at the Centro de Referencia de Alto Maé in Maputo.

Methods: We performed a retrospective analysis of data collected on patients enrolled at the CRAM between 2010 and 2015, extracting routinely-collected clinical information from patient care databases. KS treatment followed national guidelines, and KS staging followed AIDS Clinical Trials Group and MOH criteria. Baseline description of the cohort and patient outcomes was performed. Risk factors for negative outcomes (death or loss to follow-up) were explored using Cox regression.
\end{abstract}

Results: Between 2010 and 2015, 1573 patients were enrolled, and 1210 began chemotherapy. A majority were young adult males. At enrollment, CD4 was < 200 cells/ $\mu$ in 45\% of patients. Among patients receiving chemotherapy, $78 \%$ received combination doxorubicin-bleomycin-vincristine. Among patients receiving chemotherapy, 43\% were lost to follow-up and $8 \%$ were known to have died. In multivariate regression, the only risk factors identified with poor outcomes were CD4<100 cells/ $\mu$ lat enrollment (Risk ratio $1.5,95 \% \mathrm{Cl} 1.1-2.1, p=0.02$ and having S1 disease (RR 1.7, 95\% Cl 1.2-2.3, $p=0.001$ ).

Discussion: We describe a large cohort of patients receiving care for HIV-associated KS in a specialized clinic in an urban setting. Outcomes were nonetheless unsatisfactory. Efforts should be made to decrease late referrals and entry into care and to increase access to more effective and better-tolerated treatments like liposomal doxorubicin.

Keywords: Kaposi sarcoma, Acquired immunodeficiency syndrome, AIDS-related opportunistic infections, Doxorubicin, Mozambique

* Correspondence: matthew.coldiron@epicentre.msf.org

${ }^{5}$ Epicentre, 8 rue Saint-Sabin, 75011 Paris, France

Full list of author information is available at the end of the article 


\section{Introduction}

Kaposi's sarcoma (KS) is the most frequent cancer among persons living with HIV/AIDS in highresource settings [1] and is a major cause of mortality in sub-Saharan Africa [2]. In Mozambique, it is the most frequent cancer documented in cancer registers in the major cities of Maputo and Beira [3], with an estimated age-standardized incidence of 23 cases per 100,000 persons per year and an estimated 3215 deaths due to KS in Mozambique in 2012 alone [4].

$\mathrm{KS}$ is an AIDS-defining opportunistic infection and is associated with human herpes virus 8 (HHV8) infection. Advanced stage KS may cause considerable morbidity due to edema and skin and soft tissue infection, ulceration and necrosis; visceral lesions can cause acute, lifethreatening bleeding $[5,6]$. And while its classic presentation in non-immunosuppressed individuals is often indolent, current experience in sub-Saharan Africa suggests that KS can be aggressive and lead to poor outcomes [7]. The fact that KS lesions are often visible and quite painful often leads to both physical and psychological disability [8], and indeed the outcomes of some clinical trials have been based on quality of life [9].

The AIDS Clinical Trials Group (ACTG) staging system for AIDS-KS classifies patients based on three variables: tumour extent (T), immune system status (I), and evidence for HIV-associated systemic illness (S). Each variable is classified as good risk (0) or poor risk (1) [10]. These prognostic factors have been prospectively and independently validated [11].

The treatment of HIV-associated $\mathrm{KS}$ is based on reconstituting the immune system with antiretroviral therapy (ART), which has been shown to significantly reduce the burden of KS disease by itself $[12,13]$. Nonetheless, when disease is advanced, it is often necessary to add cytotoxic chemotherapy to control KS disease more quickly [14]. This is often the case in sub-Saharan Africa, where patients present with advanced disease. Several agents are effective against HIV-associated KS, including doxorubicin, vincristine, bleomycin and etoposide. In high-income countries, standard first-line chemotherapy consists of liposomal anthracyclines or taxanes [6, 15]. Pegylated liposomal formulations of doxorubicin (PLD) are associated with more favourable outcomes and safety profiles than conventional forms [16-19], and allow for monotherapy. However, in lowand middle-income countries, a combination of bleomycin and vincristine, with or without conventional doxorubicin (ABV) are more often the standard of care due to high cost and unavailability of liposomal formulations. These combinations are more poorly-tolerated and associated with lower quality of life [9].

Access to cancer treatments, including $\mathrm{KS}$, remains limited in many sub-Saharan African settings [20].
General health systems barriers include lack of medications, lack of clear guidelines, clinical staff with little oncological training, a dearth of diagnostic and monitoring tools and poor infrastructure necessary to handle cytotoxic medications [21-23]. Beyond these general concerns, KS presents a few specific challenges in lowresource settings. Decision-making about when to start and stop treatment is not easily-standardized because of the beneficial effects of ART alone, and also because of side effects associated with $\mathrm{ABV}$, the poor availability of second-line cytotoxic treatments, and because of the KS immune reconstitution inflammatory syndrome [24, 25].

To address the burden of HIV-associated KS, Médecins Sans Frontières (MSF), in collaboration with the Ministry of Health of Mozambique $(\mathrm{MOH})$, established a KS treatment unit in Maputo in 2010. In this report, we describe a large cohort of HIV-infected KS patients and their clinical outcomes. We further explore risk factors for negative outcomes such as death and loss to follow-up.

\section{Methods \\ Study setting}

The Centro de Referência de Alto-Maé (CRAM) was established in 2009 as a collaboration between the $\mathrm{MOH}$ and MSF in Chamanculo Health District, in Mozambique's capital, Maputo. The goal was to bridge the gap between primary health care and referral hospitals by ensuring access to specialized care for HIV-infected patients with complications (such as advanced disease, treatment failure and KS). CRAM provides a comprehensive package of medical, laboratory, and psychological care, including second- and third-line ART for adults and children, chemotherapy for HIV-associated KS, diagnosis and treatment of OIs, and management of side effects of ART.

\section{KS care and treatment}

CRAM officially serves an urban area with a population of approximately 350,000 persons, but given that it is one of only three KS treatment centers in Maputo, it treats many patients from outside its official catchment area. Since 2013, the pharmaceutical department of Geneva University Hospitals has supported the effective and safe management of cytotoxic drugs at CRAM, including training of clinical and paraclinical staff, infrastructure development and waste disposal.

Patients with suspected HIV-associated KS undergo a thorough clinical history and examination and are staged according to Mozambican guidelines and ACTG criteria. Historically, most dermatologic $\mathrm{KS}$ has been diagnosed clinically due to limited availability of histopathology. All cases where the clinical diagnosis is uncertain, and all cases with suspected visceral involvement, are referred 
to the tertiary-level hospital for biopsy and other invasive procedures such as bronchoscopy and endoscopy.

Care in the CRAM follows current treatment recommendations in Mozambique, which call for ART for T0 disease, and if no response after 6 months, to begin systemic chemotherapy with bleomycin and vincristine every 3-4 weeks [26]. In the case of $\mathrm{T} 1$ disease, in addition to ART, therapy with doxorubicin, vincristine and bleomycin $(\mathrm{ABV})$ is started immediately, with cycles every 3-4 weeks. For T1 patients not on ART, a delay of 2-3 weeks is recommended between initiation of ART and chemotherapy. Serum haemoglobin levels and the absolute neutrophil count are routinely monitored prior to each dose of chemotherapy. Chemotherapy is continued until remission of all cutaneous and mucosal lesions, and relief of obstructions and symptoms, including pain, improvement in function, or until the cumulative dose of $550 \mathrm{mg} /$ $\mathrm{m}^{2}$ of doxorubicin or $440 \mathrm{UI}$ of bleomycin is reached. Patients with disease progression despite the ABV therapy are referred to the dermatology department at the tertiary hospital for second-line chemotherapy.

CRAM also provides primary HIV care (ARTs, education, adherence counselling) as well as psychosocial care for its patients. KS patients also have dedicated services for wound care and analgesia. A system for tracing patients lost to follow-up through phone calls and home visits is also in place.

\section{Study design and outcome definitions}

We performed a retrospective cohort study on patients co-infected with HIV/KS, and beginning treatment with ART and/or chemotherapy from January 1, 2010 to December 31, 2015 at CRAM. Data were extracted from the routine clinical databases maintained for follow-up of patient care. Outcomes and treatment responses were judged every 3-6 cycles after initiation of KS chemotherapy per national recommendations, and therefore not routinely captured for patients who do not receive chemotherapy. Complete response (CR) is defined as resolution of any detectable disease for at least 4 weeks, including KS-associated oedema or effusion. Partial response (PR) is defined as the absence of new cutaneous, oral or visceral lesions, or the absence of worsening of tumour-associated oedema and effusions, for greater than 4 weeks. In addition, at least one of the following criteria is necessary: (1) $50 \%$ decrease in the number of previously existing skin lesions; (2) at least $50 \%$ of flattening of all previously raised lesions; (3) $50 \%$ decrease in the sum of the products of the largest perpendicular diameters of indicator lesions selected at enrolment; or (4) the patient meets criteria for CR except that residual tumour-associated oedema or effusion is present. Progressive disease is defined as new or progressive visceral lesions, worsening of tumor-related edema for at least one week, a $25 \%$ increase in the number of cutaneous lesions. Patients with no contact for a period of 6 months, after at least two attempts at tracing, were considered lost to follow-up.

\section{Data analysis}

Baseline variables and clinical outcomes were described using frequencies and percentages for categorical variables, and means or medians and measures of dispersion for continuous variables. For patients who did not receive chemotherapy, follow-up time began at the date of first visit. For patients who did receive chemotherapy, follow-up time began at the date of the first dose of chemotherapy. Follow-up time ended at the date of death, transfer, or program discharge. For patients lost to follow-up, the date of their last visit was considered their date of study exit. For patients continuing in care, the database was closed on December 31, 2015.

For patients receiving any chemotherapy, survival time until death or loss-to follow-up was described using a Kaplan-Meier survival function.

Cox regression was used to explore factors associated with death and loss to follow up, but patients who were eventually transferred to other centers were excluded from this analysis, since some were transferred for escalation of care while others were transferred because of personal preference. Covariates were included in a multivariate model if $p<0.2$ in univariate analysis. We combined death and lost to follow-up (LTFU) in the models to more conservatively estimate associations between covariates of interest and the poor outcomes. Two-sided $p$-values $<0.05$ were considered significant. All statistical analyses were performed using Stata version 14.1 (College Station, TX, USA).

\section{Ethics statement}

This research fulfilled the exemption criteria set by the Médecins Sans Frontières Ethics Review Board for a posteriori analyses of routinely collected clinical data and thus did not require MSF ERB review. It was conducted with permission from Micaela Serafini, Medical Director, Médecins Sans Frontières - Operational Center Geneva.

\section{Results}

\section{Description of the cohort}

A total of 1573 patients (including 6 HIV-negative patients) were enrolled between 2010 and 2015 (Fig. 1). The 1567 HIV-positive patients form the core clinical cohort which is described. A majority were young adult males (Table 1).

1069 (68\%) patients had already started ART prior to program enrolment, but among those patients, 512 (50\%) had been on ARV for less than 1 month, and 714 (67\%) for less than 6 months. CD4 counts were available 


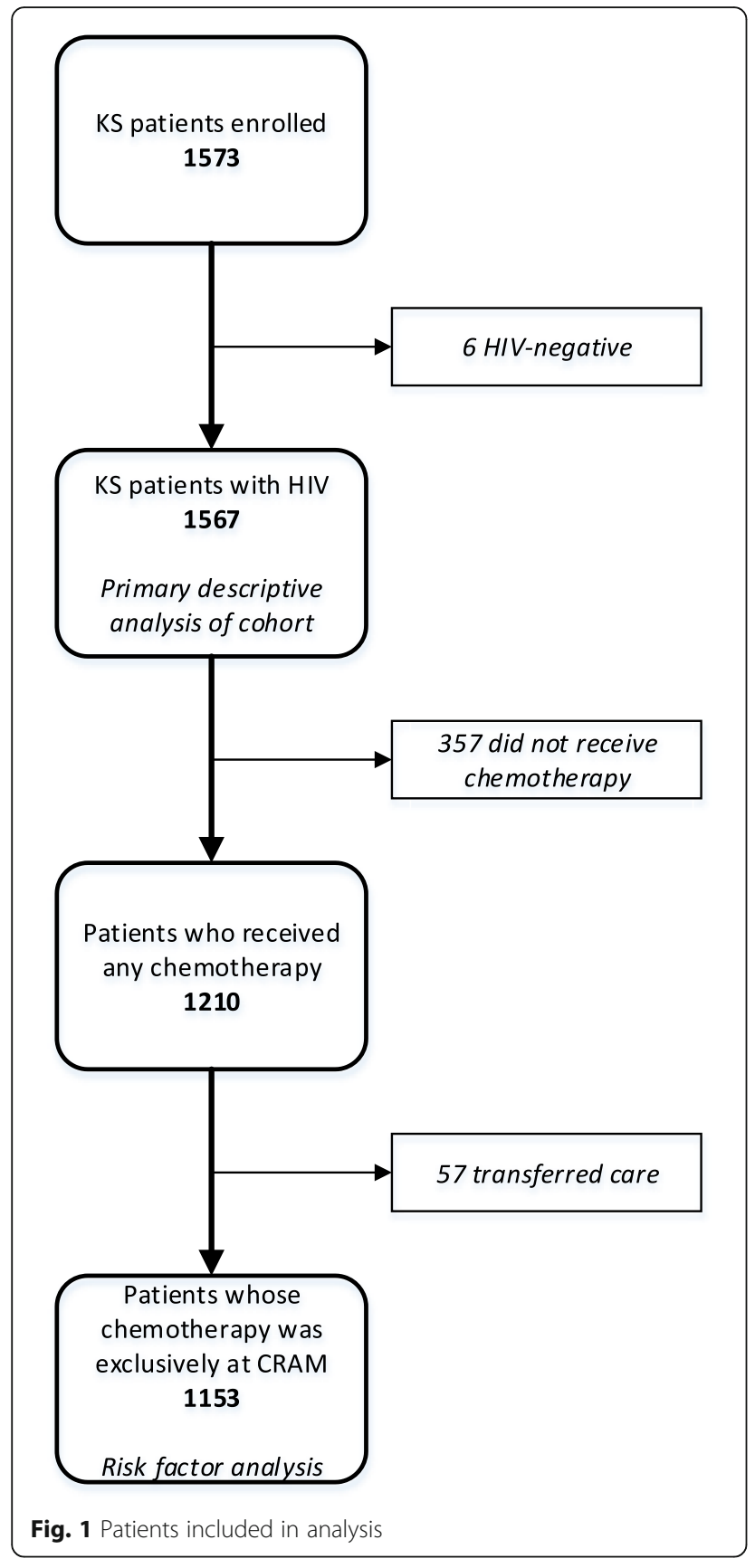

for $47 \%$ of patients at time of enrolment, of whom $55 \%$ had CD4 > 200 cells/ $\mu$ l (Table 1). HIV viral load testing was introduced in 2014, and among eligible patients (those on ARV for $>6$ months) with results, only 88/245 (36\%) had an undetectable viral load at the time of presentation.

A total of 1210 patients initiated any type of chemotherapy during the study period. Triple therapy with doxorubicin, bleomycin and vincristine was the most common combination of cytotoxic drugs given to patients receiving chemotherapy (Table 2).
Table 1 Baseline clinical description of the study population

\begin{tabular}{|c|c|c|}
\hline Characteristic & $\mathrm{n}$ & $\%$ \\
\hline \multicolumn{3}{|l|}{ Sex } \\
\hline Male & 1002 & 64 \\
\hline Female & 565 & 36 \\
\hline \multicolumn{3}{|l|}{ Age in years $(N=1564)$} \\
\hline$<15$ & 19 & 1 \\
\hline $15-29$ & 405 & 26 \\
\hline $30-44$ & 851 & 54 \\
\hline$\geq 45$ & 289 & 19 \\
\hline \multicolumn{3}{|l|}{ BMI $(N=1490)$} \\
\hline$<18.5$ & 177 & 12 \\
\hline$\geq 18.5$ & 1313 & 88 \\
\hline \multicolumn{3}{|l|}{ History of ART $(N=1461)$} \\
\hline ART prior to referral & 1069 & 73 \\
\hline No ART prior to referral & 392 & 27 \\
\hline \multicolumn{3}{|l|}{ CD4, cells/Ml $(N=732)$} \\
\hline$<100$ & 181 & 25 \\
\hline 100-199 & 145 & 20 \\
\hline $200-349$ & 199 & 27 \\
\hline$\geq 350$ & 207 & 28 \\
\hline \multicolumn{3}{|c|}{ Kaposi Sarcoma Stage $(N=1474)$} \\
\hline TOSO & 192 & 13 \\
\hline TOS1 & 54 & 4 \\
\hline T150 & 913 & 62 \\
\hline T1S1 & 309 & 21 \\
\hline
\end{tabular}

\section{Response to treatment}

Among patients receiving chemotherapy, the median length of follow-up time was 14.1 months (IQR 6.523.9). A total of 122 (8\%) patients were known to have died, but $678(43 \%)$ were lost to follow-up (Table 3, Fig. 2). The proportion of patients lost to follow-up was higher among patients not receiving chemotherapy than among those who did.

Among patients receiving chemotherapy known to be alive when they exited care, 312/682 (46\%) had received $\geq 11$ cycles. On the other hand, $57 \%$ of patients who died

Table 2 History of Kaposi sarcoma treatment

\begin{tabular}{lll}
\hline Initial KS treatment regimen & $\mathrm{N}$ & $\%$ \\
\hline Cytotoxic chemotherapy & 1210 & 77 \\
Doxorubicin-bleomycin-vincristine & 940 & 78 \\
Bleomycin-vincristine & 174 & 14 \\
Other chemotherapy regimens* & 96 & 8 \\
Antiretroviral therapy alone & 357 & 23 \\
\hline
\end{tabular}

*Includes doxorubicin-bleomycin, doxorubicin-vincristine, and $\mathrm{ABV}$-methotrexate

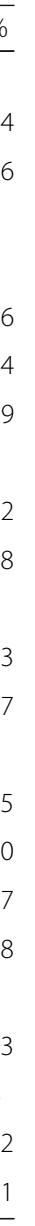


Table 3 Vital status at time of exit from care

\begin{tabular}{|c|c|c|c|c|c|c|}
\hline \multirow[b]{2}{*}{ Outcome } & \multicolumn{2}{|c|}{ ARV alone $(N=357)$} & \multicolumn{2}{|c|}{ Chemotherapy $(N=1210)$} & \multicolumn{2}{|c|}{ Cohort $(N=1567)$} \\
\hline & $n$ & $\%$ & $n$ & $\%$ & $\mathrm{~N}$ & $\%$ \\
\hline Died & 33 & 9 & 89 & 7 & 122 & 8 \\
\hline Known alive & 85 & 24 & 682 & 56 & 767 & 49 \\
\hline Lost to follow up & 239 & 67 & 439 & 36 & 678 & 43 \\
\hline
\end{tabular}

and $55 \%$ of patients who were lost to follow up did so after receiving $\leq 5$ cycles of chemotherapy (Fig. 3 ).

Information on disease progression among patients receiving chemotherapy is incomplete, but is available for 517 patients, of whom 62 (12\%) achieved complete remission and 448 (87\%) ever achieved partial remission. A total of 5 patients had stable disease after treatment and 2 had progressive disease. Among patients achieving complete or partial remission, the median number of cycles of chemotherapy received was 12 (IQR 8-17, range 1-27).

Having a CD4 $<100$ cells/ $\mu$ land having S1 disease at presentation were significantly associated with poor outcomes (loss to follow-up or death). No other risk factors were associated with poor outcomes in univariate or multivariate analysis (Table 4).

\section{Discussion}

We describe one of the largest cohorts of KS patients in sub-Saharan Africa, treated in an urban secondary-level health facility. This specialty centre has a comprehensive package for the treatment of KS, and is based on collaboration between $\mathrm{MOH}$ and MSF, with technical support from the Geneva University Hospital. Nonetheless, despite all of these advantages, our results show many of the challenges inherent with the treatment of KS in Africa today, and suggest a clear agenda for improving quality of care for patients with HIV-associated KS moving forward.

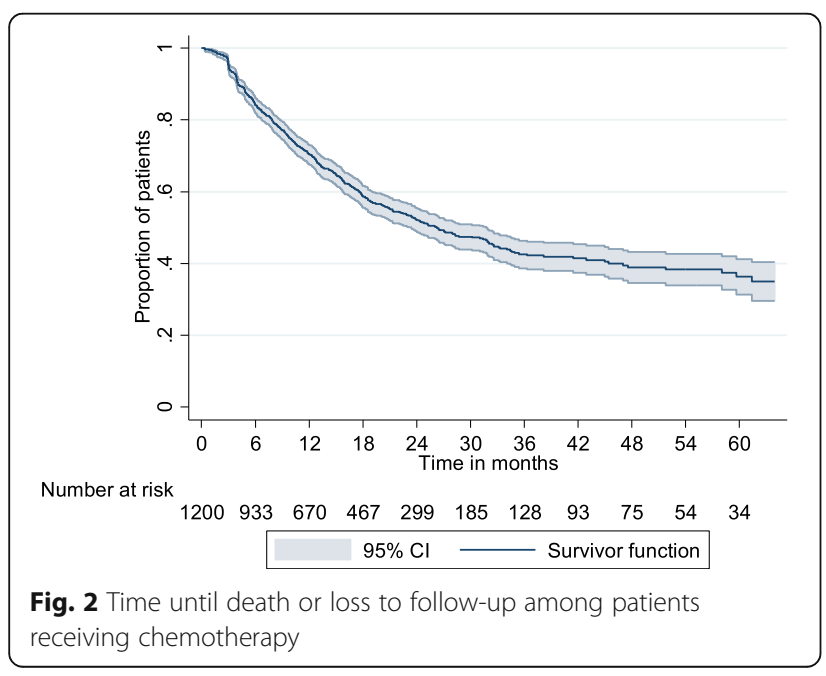

The typical KS patient was a relatively young male who presented with relatively advanced immunosuppression (half had CD4 $<200$ at enrolment, and most had started ART in the previous 6 months) and significant burden of KS disease (83\% with T1 disease, $25 \%$ with $\mathrm{S} 1$ disease). These patients are broadly similar to many other cohorts described, in both rural and urban areas, and in primary care and referrallevel centers in southern Africa [7, 27, 28] It is also important to point out that only half of our patients had CD4 available at baseline, likely because most presented with Stage IV HIV disease, which did not warrant immediate CD4 measurement according to guidelines during most of the follow-up period. The actual proportion of patients with $\mathrm{CD} 4<200$ at enrollment was likely to be even higher. In any case, these "late presentations" mean that innovation in screening and early referral both at primary health facilities and also in the community is desperately needed.

Patients arriving with advanced KS disease were at high risk of attrition and had an overall poor prognosis. It is likely in this setting, where patient tracing was incomplete, that many of those patients lost to follow-up represent unrecorded deaths [7]. It is important to note that the contact tracing was performed under routine program conditions, and is not necessarily analogous to the rigorous contact tracing systems that one might expect to find in a clinical trial. Nonetheless, rates of loss to follow-up as high

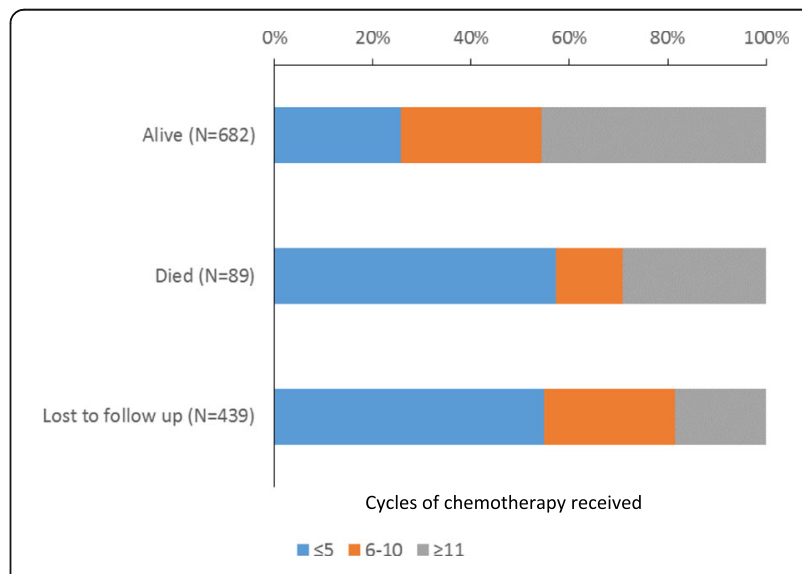

Fig. 3 Cycles of chemotherapy received by patient vital status 
Table 4 Factors associated with death or loss to follow-up $(N=1153)$

\begin{tabular}{|c|c|c|c|c|c|c|c|}
\hline \multirow[b]{2}{*}{ Characteristic } & \multirow[b]{2}{*}{ n (\%) } & \multicolumn{3}{|c|}{ Univariate Analysis } & \multicolumn{3}{|c|}{ Multivariate Analysis } \\
\hline & & $\mathrm{HR}$ & $95 \% \mathrm{Cl}$ & $p$ & $\mathrm{HR}$ & $95 \% \mathrm{Cl}$ & $p$ \\
\hline \multicolumn{8}{|l|}{ Sex } \\
\hline Female & $416(36)$ & ref & & & ref & & \\
\hline Male & $737(64)$ & 1.1 & $0.9-1.4$ & 0.16 & 1.1 & $0.8-1.5$ & 0.6 \\
\hline \multicolumn{8}{|l|}{ Age in years } \\
\hline$<35$ & $599(52)$ & ref & & & & & \\
\hline$\geq 35$ & $554(48)$ & 0.9 & $0.8-1.1$ & 0.35 & & & \\
\hline \multicolumn{8}{|c|}{ Baseline CD4 (cell/ $\left./ \mathrm{mm}^{3}\right)(N=583)$} \\
\hline$\geq 100$ & $451(77)$ & ref & & & ref & & \\
\hline$<100$ & $132(23)$ & 1.5 & $1.1-2.1$ & 0.02 & 1.5 & $1.1-2.1$ & 0.02 \\
\hline \multicolumn{8}{|c|}{ Tumour extension $(N=1120)$} \\
\hline T0 & $169(15)$ & ref & & & & & \\
\hline $\mathrm{T} 1$ & $951(85)$ & 1.0 & $0.8-1.3$ & 0.94 & & & \\
\hline \multicolumn{8}{|c|}{ Systemic disease $(n=1120)$} \\
\hline so & 881 (79) & ref & & & ref & & \\
\hline S1 & $239(21)$ & 1.7 & $1.4-2.0$ & $<0.001$ & 1.7 & $1.2-2.3$ & 0.001 \\
\hline \multicolumn{8}{|l|}{ ART at baseline } \\
\hline No & $316(27)$ & ref & & & & & \\
\hline Yes & 837 (73) & 1.1 & $0.9-1.3$ & 0.5 & & & \\
\hline
\end{tabular}

*HR: hazard ratio

as $40 \%$ have been described in other cohorts in subSaharan Africa [29], but in other settings, retention in care at one year approaches $80 \%$ [28].

Data on side effects and tolerability are not routinely collected in the CRAM, but our subjective experience is that standard ABV is poorly-tolerated by many patients with advanced disease and immunosuppression. In the immediate term, vomiting and the myelosuppressive effects of doxorubicin are frequent; bacterial superinfection and sepsis can delay chemotherapy delivery. In the intermediate term, the development of neuropathies related to vincristine can exacerbate already-severe pain related to the massive lymphedema seen in many patients with advanced disease. In the end, whether poor outcomes are caused by KS, by advanced HIV (or opportunistic infections), or by a poorly-tolerated treatment, we have clearly described a vicious cycle that is difficult to overcome, even in an "ideal" specialized setting.

Data on disease progression was incomplete, so it is difficult to draw definitive conclusions about the effectiveness of treatment. Nonetheless, we note that a median of 12 cycles of chemotherapy to reach remission. This may be partly due to a lack of standardization of disease progression measures in daily clinical practice, but it also likely represents overtreatment. As soon functional capacity has returned, and the patient has appropriate social support, ART alone could be tested, even among patients who begin with advanced disease, as it has been associated with reasonable improvement in quality of life [30]. Treatment response needs to be judged more quickly, and with the understanding that complete remission will be very rare among patients presenting with advanced disease and particularly those with lymphedema. The illogical paradigm of "treat until toxic cumulative doses are reached" should be rethought. Once pain and edema are brought under control, chemotherapy can be stopped, or at least used less frequently, while full immune reconstitution with ART takes place.

One of the easiest potential solutions to this cycle of problems would be to use simpler chemotherapies such as oral etoposide or lenalidomide for early-stage disease, but lenalidomide has been poorly studied in similar contexts [31], and two recent multicentric trials that included etoposide at African sites have been stopped early because of poor performance of etoposide [32, 33]. Another solution would be to increase access to "gold standard" chemotherapies that are available in the global north, such as PLD or taxanes. PLD has a favourable side effect profile, and its potential for monotherapy make it ideal for settings similar to the one we describe, but its high cost means that it is currently not realistic for widespread use in sub-Saharan Africa. A pilot program using PLD is currently underway in the CRAM; if successful, it could be used to leverage a market and reduce prices. At a health-systems level, this kind of innovation creates opportunities to develop specialized outpatient oncological platforms.

The use of routinely-collected program data reflects realities in the field, and is one of the strengths of our analysis. To our knowledge, cohorts of similar size and length of follow-up have not been reported. Nonetheless, our findings come with limitations related to the nature of the data collection process, which has been fragmented over the years, and which is often seen as being of secondary importance in a busy, real-world program setting. The high proportion of patients lost to follow-up also makes some outcome data difficult to interpret. Future research, including using qualitative methods, is needed for a better understanding of the reasons for loss to follow-up. The results of this single-center, retrospective study may not be generalizable to other settings in sub-Saharan Africa. As one of only three referral centers where chemotherapy is given in Maputo, CRAM likely receives a disproportionate share of severe cases, and outcomes for patients with less-advanced disease, who may be treated in the community with ARV alone, may be different. 


\section{Conclusions}

We describe a large cohort of patients with HIV-associated $\mathrm{KS}$ in a secondary health facility in a low-resource urban setting. Despite structural advantages of the program, these patients have had relatively poor outcomes with high loss to follow-up. Urgent measures are required to address this, including increasing ART coverage and improving early access to ART, working with clinicians and community members to decrease time to recognition of KS and referral, and changing old treatment protocols to include more effective and better-tolerated chemotherapy such as PLD. This last point will necessarily involve increasing access, lowering price, and obtaining regulatory approvals of newly-appearing generic PLD products. Given the high burden of disease, this should be a main priority of policymakers in the most-affected countries.

\section{Abbreviations}

ABV: Combination therapy with doxorubicin, bleomycin and vincristine; ACTG: AIDS Clinical Trial Group; AIDS: Acquired Immunodeficiency Syndrome; ART: Antiretroviral therapy; CRAM: Centro de Referência de Alto-Maé; HHV8: Human herpesvirus 8; HIV: Human immunodeficiency virus; KS: Kaposi's sarcoma; LTFU: Loss to follow-up; MOH: Ministry of Health; MSF: Médecins Sans Frontières; PLD: Pegylated liposomal doxorubicin

\section{Acknowledgements}

The authors thank Raquel Bandeira for assistance with data analysis, JeanPaul Kimenyi for work on data collection, the clinical staff of the CRAM, and the patients of the CRAM.

\section{Ethics statement}

This research fulfilled the exemption criteria set by the Médecins Sans Frontières Ethics Review Board for a posteriori analyses of routinely collected clinical data and thus did not require MSF ERB review. It was conducted with permission from Micaela Serafini, Medical Director, Médecins Sans Frontières - Geneva Operational Center.

\section{Funding}

Médecins Sans Frontières provided funding for the collection, analysis, and interpretation of the data.

\section{Availability of data and materials}

The datasets used and/or analyses during the current study are available from the corresponding author on reasonable request.

\section{Authors' contributions}

VF performed data analysis and wrote the first draft. LM coordinated patient care and revised the manuscript. AGZ provided direct patient care. RM and $\mathrm{GL}$ provided medical consultation. IC coordinated data collection and analysis and revised the manuscript. LTT provided expert guidance and training in the field and revised the manuscript. MC wrote the final draft of the manuscript and provided support for data collection activities. All authors read and approved the final manuscript.

\section{Consent for publication}

Not applicable.

\section{Competing interests}

The authors declare that they have no competing interests.

\section{Publisher's Note}

Springer Nature remains neutral with regard to jurisdictional claims in published maps and institutional affiliations.

\section{Author details}

${ }^{1}$ Médecins Sans Frontières, Maputo, Mozambique. ${ }^{2}$ Ministry of Health, Maputo, Mozambique. ${ }^{3}$ Médecins Sans Frontières, Geneva, Switzerland. ${ }^{4}$ Hôpitaux Universitaires de Genève, Geneva, Switzerland. ${ }^{5}$ Epicentre, 8 rue Saint-Sabin, 75011 Paris, France.

Received: 17 October 2017 Accepted: 11 January 2018

Published online: 19 January 2018

\section{References}

1. Hernández-Ramírez RU, Shiels MS, Dubrow R, Engels EA. Cancer risk in HIVinfected people in the USA from 1996 to 2012: a population-based, registrylinkage study. Lancet HIV. 2017; https://doi.org/10.1016/S23523018(17)30125-X

2. Casper $\mathrm{C}$. The increasing burden of HIV-associated malignancies in resourcelimited regions. Annu Rev Med. 2011;62:157-70. https://doi.org/10.1146/ annurev-med-050409-103711.

3. Carrilho C, Ferro J, Lorenzoni C, Sultane T, Silva-Matos C, Lunet N. A contribution for a more accurate estimation of the incidence of Kaposi sarcoma in Mozambique. Int J Cancer. 2012:132:988-9.

4. Globocan 2012: Estimated cancer incidence mortality and prevalance worldwide in 2012. Fact Sheets by Population. http://globocan.iarc.fr/Pages/ fact_sheets_population.aspx. Accessed 26 Jul 2017

5. Martellotta F, Berretta M, Vaccher E, Schioppa O, Zanet E, Tirelli U. AIDSrelated Kaposi'S sarcoma: state of the art and therapeutic strategies. Curr HIV Res. 2009;7:634-8. http://www.ncbi.nlm.nih.gov/pubmed/19929800. Accessed 26 Jul 2017

6. Uldrick TS, Whitby D. Update on KSHV-epidemiology, Kaposi sarcoma pathogenesis, and treatment of Kaposi sarcoma. Cancer Lett. 2011;205:15062. https://doi.org/10.1016/j.canlet.2011.02.006.

7. Chu KM, Mahlangeni G, Swannet S, Ford NP, Boulle A, Van Cutsem G. AIDSassociated Kaposi's sarcoma is linked to advanced disease and high mortality in a primary care HIV programme in South Africa. J Int AIDS Soc. 2010;13:23. https://doi.org/10.1186/1758-2652-13-23.

8. de Moore GM, Hennessey P, Kunz NM, Ferrando SJ, Rabkin JG. Kaposi's sarcoma: The Scarlet Letter of AIDS: the psychological effects of a skin disease. Psychosomatics. 41:360-3. http://www.ncbi.nlm.nih.gov/pubmed/ 10906360. Accessed 26 Jul 2017.

9. Osoba D, Northfelt DW, Budd DW, Himmelberger D. Effect of treatment on health-related quality of life in acquired immunodeficiency syndrome (AIDS)-related Kaposi's sarcoma: a randomized trial of pegylated-liposomal doxorubicin versus doxorubicin, bleomycin, and vincristine. Cancer Investig. 2001;19:573-80. https://doi.org/10.1081/CNV-100104284.

10. Krown SE, Metroka C, Wernz JC. Kaposi's sarcoma in the acquired immune deficiency syndrome: a proposal for uniform evaluation, response, and staging criteria. AIDS Clinical Trials Group oncology committee. J Clin Oncol. 1989:7:1201-7. https://doi.org/10.1200/JCO.1989.7.9.1201.

11. Boffi El Amari E, Toutous-Trellu L, Gayet-Ageron A, Baumann M, Cathomas $\mathrm{G}$, Steffen I, et al. Predicting the evolution of Kaposi sarcoma, in the highly active antiretroviral therapy era. AIDS. 2008;22:1019-28. https://doi.org/10. 1097/QAD.0b013e3282fc9c03.

12. Bower M, Fox P, Fife K, Gill J, Nelson M, Gazzard B. Highly Active antiretroviral therapy (HAART) prolongs time to treatment failure in Kaposi's sarcoma. AIDS. 1999;13:2105-11. http://www.ncbi.nlm.nih.gov/pubmed/ 10546864. Accessed 26 Jul 2017

13. Bower M, Weir J, Francis N, Newsom-Davis T, Powles S, Crook T, et al. the effect of HAART in 254 consecutive patients with AIDS-related Kaposi's sarcoma. AIDS. 2009;23:1701-6. https://doi.org/10.1097/QAD. 0b013e32832d080d.

14. Martin-Carbonero L, Barrios A, Saballs P, Sirera G, Santos J, Palacios R, et al. Pegylated liposomal doxorubicin plus highly active antiretroviral therapy versus highly active antiretroviral therapy alone in HIV patients with Kaposi's sarcoma. AIDS. 2004;18:1737-40. http://www.ncbi.nlm.nih.gov/pubmed/ 15280789. Accessed 26 Jul 2017

15. Di Lorenzo G, Konstantinopoulos PA, Pantanowitz L, Di Trolio R, De Placido S, Dezube BJ. Management of AIDS-related Kaposi's sarcoma. Lancet Oncol. 2007:8:167-76.

16. Rafiyath SM, Rasul M, Lee B, Wei G, Lamba G, Liu D. Comparison of safety and toxicity of liposomal doxorubicin vs. conventional anthracyclines: a meta-analysis. Exp Hematol Oncol. 2012;1:10. 
17. Martín-Carbonero L, Palacios R, Valencia E, Saballs P, Sirera G, Santos I, et al. long-term prognosis of HIV-infected patients with Kaposi sarcoma treated with Pegylated liposomal doxorubicin. Clin Infect Dis. 2008:47:410-7. https:// doi.org/10.1086/589865.

18. Northfelt DW, et al. Pegylated-liposomal doxorubicin versus doxorubicin, rrbleomycin, and vincristine in the treatment of AIDS-related Kaposi's sarcoma: Irresults of a randomized phase III clinical trial. J Clin Oncol. 1998;16

19. Stewart S, Jablonowski H, Goebel FD, Arasteh K, Spittle M, Rios A, et al. randomized comparative trial of pegylated liposomal doxorubicin versus bleomycin and vincristine in the treatment of AIDS-related Kaposi's sarcoma. J Clin Oncol. 1998;16:683-91.

20. Sitas F, Parkin DM, Chirenje M, Stein L, Abratt R, Wabinga H. Part II: cancer in indigenous Africans-causes and control. Lancet Oncol. 2008;9:786-95.

21. Kerr DJ, Midgley R. Can we treat cancer for a dollar a day? Guidelines for low-income countries. N Engl J Med. 2010;363:801-3.

22. Farmer P, Frenk J, Knaul FM, Shulman LN, Alleyne G, Armstrong L, et al. Expansion of cancer care and control in countries of low and middle income: a call to action. Lancet. 2010;376:1186-93.

23. Krown SE. Treatment strategies for Kaposi sarcoma in sub-Saharan Africa: challenges and opportunities. Curr Opin Oncol. 2011;23:463-8. https://doi. org/10.1097/CCO.0b013e328349428d.

24. Krown SE. Highly active antiretroviral therapy in AIDS-associated Kaposi's sarcoma: implications for the design of therapeutic trials in patients with advanced, symptomatic Kaposi's sarcoma. J Clin Oncol. 2004;22:399-402.

25. Achenbach CJ, Harrington RD, Dhanireddy S, Crane HM, Casper C, Kitahata MM. Paradoxical immune reconstitution inflammatory syndrome in HIVinfected patients treated with combination antiretroviral therapy after AIDSdefining opportunistic infection. Clin Infect Dis. 2012;54:424-33.

26. Ministry of Public Health. Guide for antiretroviral treatment and opportunistic infections in adults, children, adolescents and pregnant women [in Portuguese]. Maputo, Mozambique; 2013.

27. Sengayi MM, Kielkowski D, Egger M, Dreosti L, Bohlius J. Survival of patients with Kaposi ' $s$ sarcoma in the south African antiretroviral treatment era : a retrospective cohort study. S Afr Med J. 2017;107:871-6. https://doi.org/10. 7196/SAMJ.2017.v107i10.12362

28. Herce ME, Kalanga N, Wroe EB, Keck JW, Chingoli F, Tengatenga L, et al. Excellent clinical outcomes and retention in care for adults with HIVassociated Kaposi sarcoma treated with systemic chemotherapy and integrated antiretroviral therapy in rural Malawi. J Int AIDS Soc. 2015;18: 19929. https://doi.org/10.7448/IAS.18.1.19929.

29. Bekolo CE, Soumah MM, Tiemtore OW, Diallo A, Yuma J-D, Di SL, et al. Assessing the outcomes of HIV-infected persons receiving treatment for Kaposi sarcoma in Conakry-Guinea. BMC Cancer. 2017;17 https://doi.org/10 1186/s12885-017-3771-x.

30. Mosam A, Shaik F, Uldrick TS, Esterhuizen T, Friedland GH, Scadden DT, et al. A randomized controlled trial of highly active antiretroviral therapy versus highly active antiretroviral therapy and chemotherapy in therapy-naive patients with HIV-associated Kaposi sarcoma in South Africa. JAIDS J Acquir Immune Defic Syndr. 2012;60:150-7. https://doi.org/10.1097/QAl. Ob013e318251aedd.

31. Steff M, Joly V, Di Lucca J, Feldman J, Burg S, Sarda-Mantel L, et al. Clinical activity of Lenalidomide in visceral human immunodeficiency virus-related Kaposi sarcoma. JAMA Dermatology. 2013;149:1319. https://doi.org/10.1001/ jamadermatol.2013.5751.

32. AIDS-Kaposi's Sarcoma Study Changed Due to Drug Underperformance $\mathrm{NIH}$ : National Institute of Allergy and Infectious Diseases. https://www.niaid. nih.gov/news-events/aids-kaposi's-sarcoma-study-changed-due-drugunderperformance. Accessed 15 Dec 2017.

33. AIDS-Kaposi's Sarcoma Study Ended | NIH: National Institute of Allergy and Infectious Diseases. https://www.niaid.nih.gov/news-events/aids-kaposi'ssarcoma-study-ended. Accessed 15 Dec 2017.

\section{Submit your next manuscript to BioMed Central and we will help you at every step:}

- We accept pre-submission inquiries

- Our selector tool helps you to find the most relevant journal

- We provide round the clock customer support

- Convenient online submission

- Thorough peer review

- Inclusion in PubMed and all major indexing services

- Maximum visibility for your research

Submit your manuscript at www.biomedcentral.com/submit
Biomed Central 